\title{
Interaction of collar roof with the bottom support structure of a building
}

\author{
Josef Musilek ${ }^{1, *}$ \\ ${ }^{1}$ Institute of Technology and Business in České Budějovice, Department of Civil Engineering, \\ Okružní 517/10, 37001 České Budějovice, Czech Republic
}

\begin{abstract}
Collar roofs belong to the traditional structures used for roofing buildings. In present, the collar roofs are widely used for their ability to omit internal vertical support structures (columns, support walls), which might be sometimes a complication during a design of the layout of the building. Collar roof acts on the bottom support structure of the building by quite big lateral horizontal forces. These forces are being often neglected in common practice. This fact leads to failures of the bottom support structures. Reinforced concrete rim made on the top of the brick wall is one of the methods, how to deal with these horizontal forces. The article deals with the interaction. The article deals with the interaction between the structure of the collar roof and the reinforced concrete rim.
\end{abstract}

\section{Introduction}

Collar roofs are historically one of the oldest systems that have been used throughout all periods and since their expansion in the Middle Ages they are one of the most widespread construction systems. Their significance is noticeable at present as they are very often used for roofing of simple roofs of smaller objects. Collar roofs allow to free up ground floor layout because they do not require internal vertical support elements. However, the collar roofs cause a significant lateral horizontal force on the lower support structure in the area of anchoring in the lace, which, unfortunately, is often underestimated and not considered in practice. The effects of these forces are even greater than in the case of plain or purple systems. This often leads to disturbances of the lower bearing structure of the walls, because the walls are made from common bricks, and are not able to pass these horizontal forces.

One way to capture these transverse horizontal forces is to design a reinforced concrete rim to be carried out at the top of the wall. This reinforced concrete rim then acts as a horizontal continuous beam that transmits horizontal forces from the roof. Horizontal support of this beam is made of shielded walls, where the rim is sufficiently covered or otherwise anchored and then internal support. The inner supports can be formed either by pulling the rim into the inner transverse load-bearing wall or, for example, by using a steel rod anchored to the supporting structure of the ceiling, which may optionally be hidden, for example, in a non-load-bearing wall. This reinforced concrete rim has to be dimensioned to

\footnotetext{
*Corresponding author: musilek@mail.vstecb.cz
} 
transfer horizontal load from hornbeam truss. However, the question of how far the rigidity of this reinforced concrete rim affects the behavior of the individual truss connections, it means the internal forces in the individual bonds and the individual horizontal forces, can arise. On the example of a concrete roof, a calculation will be made which will try to take into account the compliance of the reinforced concrete rim.

\section{Specification of the roof for calculation}

Layout and the section of the roof is show on the Fig. 1.
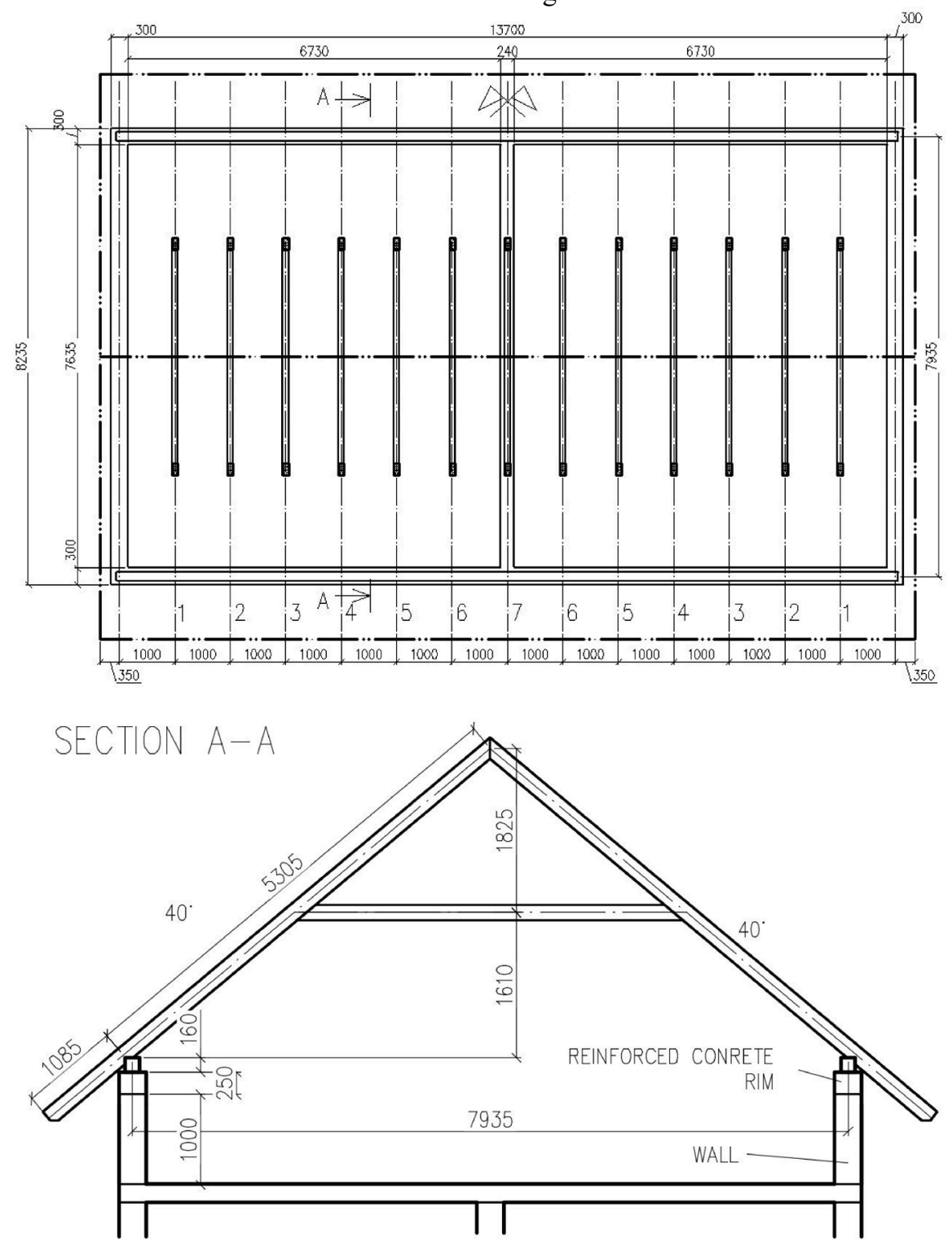

Fig. 1 Layout and the section of the roof. 
It is a roof of a typical family house of a rectangular ground plan. In the middle of the house there is one transverse wall into which a reinforced concrete rim is inserted. The rim is further introduced into the gable walls. Concrete C20 / 25 concrete material. B500B reinforcement material. Diameter of the reinforcement bars is $14 \mathrm{~mm}$.. The reinforcement scheme is in Fig. 2.

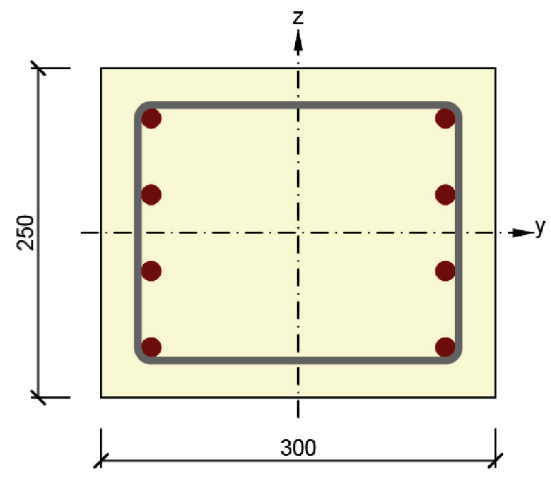

Fig. 2 Reinforcement of the rim.

It is assumed that the reinforced concrete rim is designed according to the present valid standards, for example [1], or [2] and the timber structure is designed for example according to [3] or [4].

\section{Computational model}

The computational model considers a reinforced concrete rim, which is simulated as a beam of C20/25 isotropic concrete. The reinforcement of the rim cross section is not taken into account in this calculation. This computational model also does not consider the fact that concrete can't transfer the tension (practically is transmitted by the tension reinforcement) and also does not consider reducing the bending stiffness of the rim due to cracks. Spatial computing model is at Fig. 3

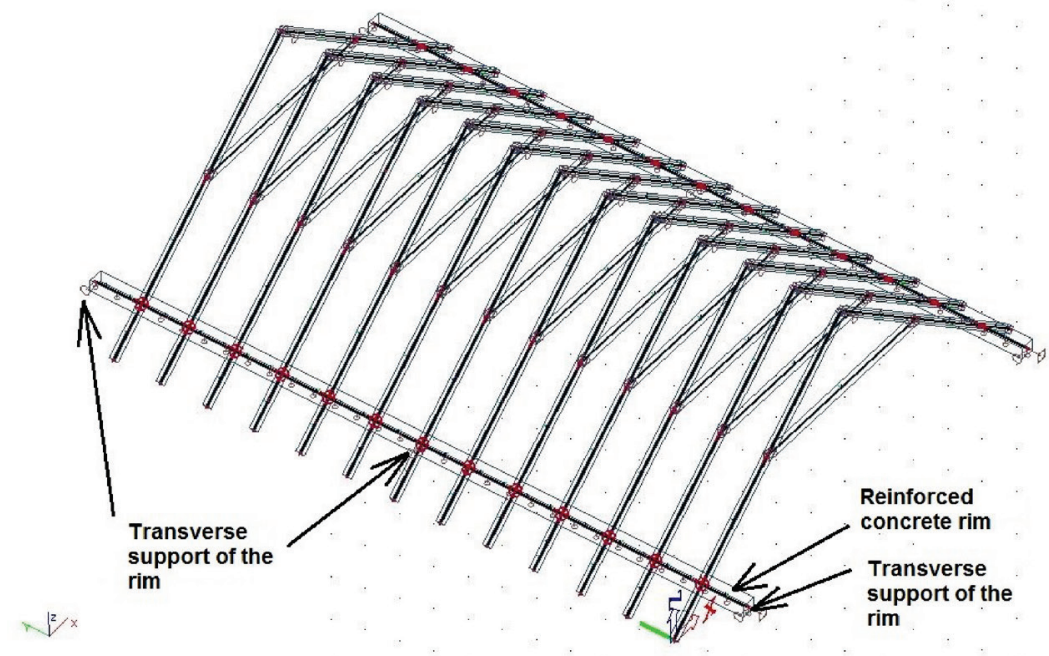

Fig. 3 Computational model. 
The rim is modeled as a continuous beam, which is vertically supported continuously in the vertical direction. It is assumed that cracks will not occur. In the transverse (horizontal) direction it is supported at its ends at the gable walls and in the center of the building at the site of the considered internal cross-sectional wall. Fig. 4 shows the shape and size of the bending moment from the considered load combination on the rafters in row no.7. Row no. 7 is located at the transverse load bearing wall which supply the rigid transverse support for the rim. The horizontal displacement at this point is zero, as is commonly contemplated in the ideal collar roof system. The Fig. 5 shows the bending moment on the rafters for the row no. 3. It can be seen that the lateral horizontal deformation of the rim caused a change in the internal forces in rafters compared to the row no. 7. In Table 1 you can see other selected results of internal forces and deformations for the third and seventh row.

The Fig. 6 shows the bending moment on the rim, which is assumed as ideally rigid. The Fig. 7 shows the bending moment on the rim assumed made from material C20/25.

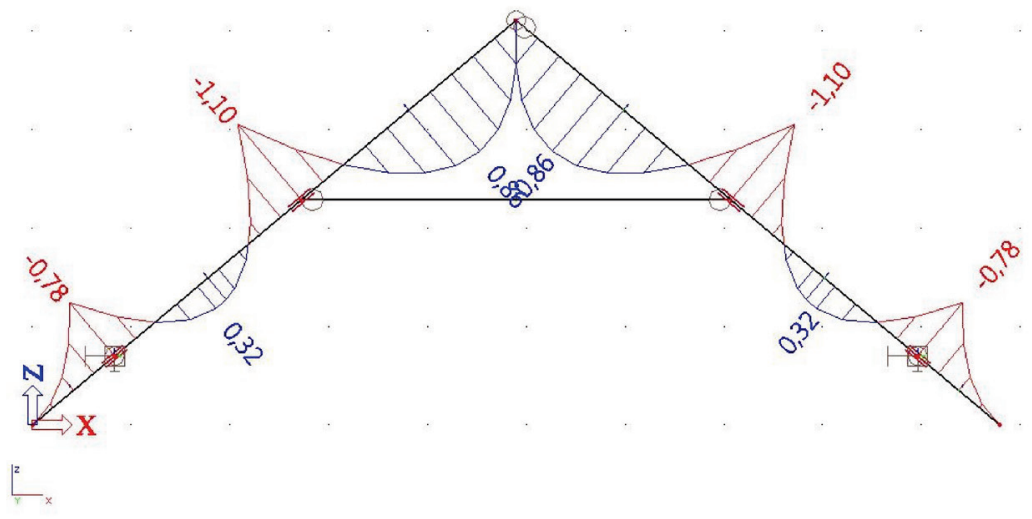

Fig. 4 Shape and size of the bending moment on the rafters in the row no. $7[\mathrm{kNm}]$.

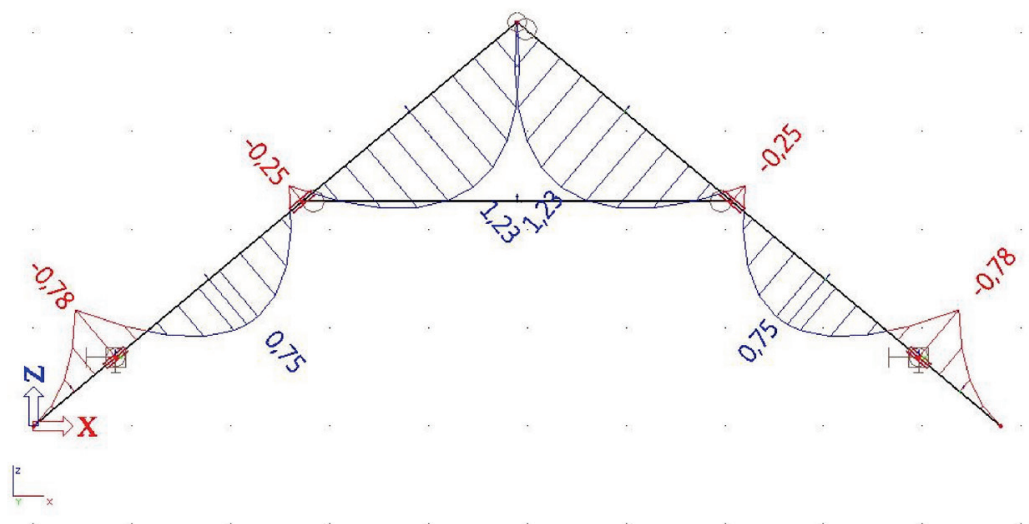

Fig. 5 Shape and size of the bending moment on the rafters in the row no. $3[\mathrm{kNm}]$. 
Table 1. Selected results.

\begin{tabular}{|c|c|c|c|c|}
\hline \multirow{2}{*}{ Row } & $\begin{array}{c}\text { Normal force } \\
\text { in collar beam } \\
(\text { compression }) \\
{[\mathrm{kN}]}\end{array}$ & $\begin{array}{c}\text { Transverse } \\
\text { horizontal } \\
\text { force into the } \\
\text { rim }[\mathrm{kN}]\end{array}$ & $\begin{array}{c}\text { Transverse } \\
\text { displacement } \\
\text { of the rim } \\
{[\mathrm{mm}]}\end{array}$ & $\begin{array}{c}\text { Max transverse } \\
\text { displacement of } \\
\text { the rim [mm] }\end{array}$ \\
\hline 7 & 8.41 & 10.74 & 0.0 & \multirow{2}{*}{8.0} \\
\hline 3 & 7.41 & 10.22 & 8.0 & \\
\hline
\end{tabular}

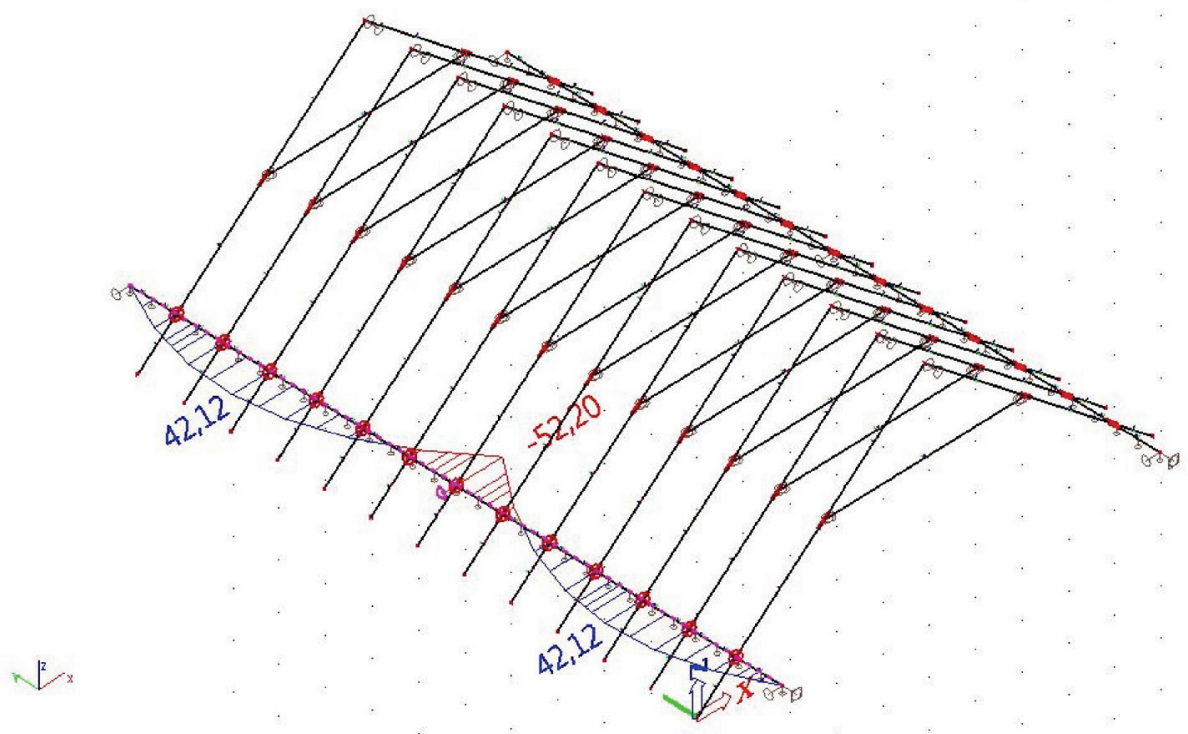

Fig. 6 Shape and size of the bending moment on the rim, which is assumed as ideally rigid [kNm].

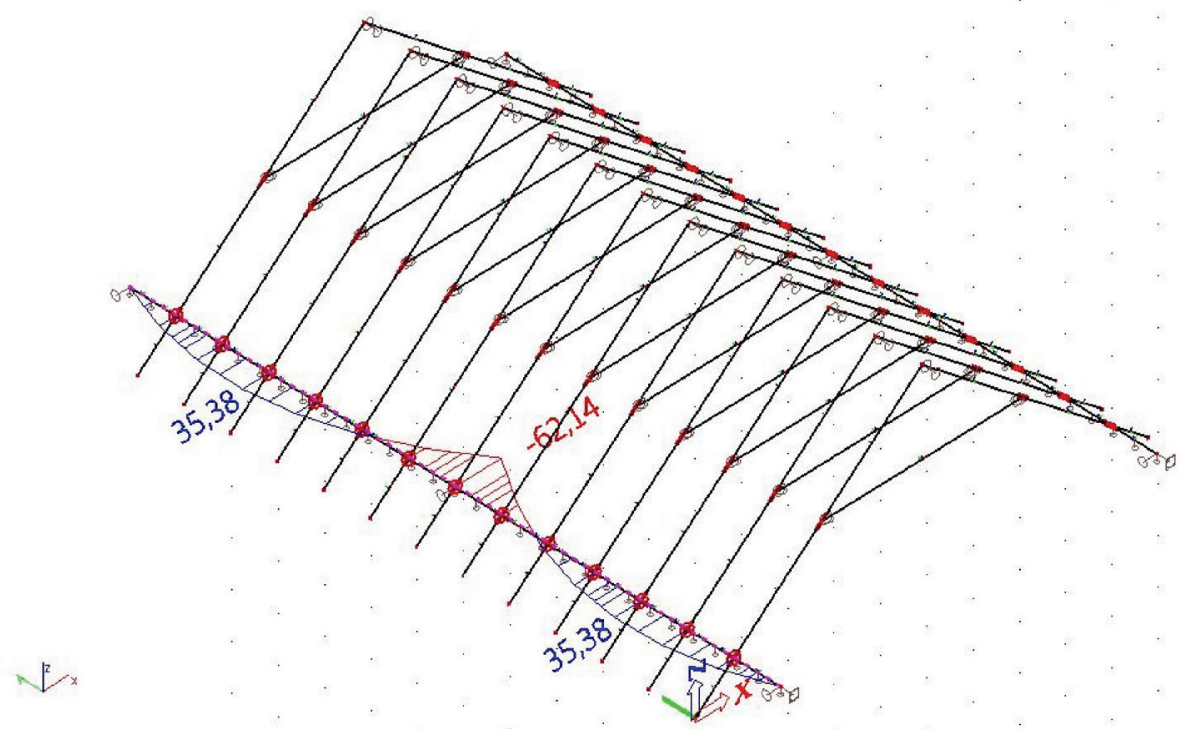

Fig. 7 Shape and size of the bending moment on the rim, which is assumed as concrete C20/25 without cracks $[\mathrm{kNm}]$. 


\section{Conclusion}

This paper presents how to integrate the horizontal rigidity of a reinforced reinforcing wreath into a global hull truss analysis. This procedure assumes the rim as an isotropic flexible bead of plain concrete that also acts under pressure and tension. The rows found in the lateral support of the rim are possible to consider as an ideal collar roof behaviour.

It is possible to see, that the rows near the middle of span of the rim show differences in internal forces compared to rows near the transverse supports. The rows near the middle of span of the rim act on the rim by smaller transverse force than the rows near the transverse rim supports. This fact corresponds to the change of force in collar beam.

However, the computational model presented in this paper doesn't take into account the influence of the reinforcement of the rim and also the influence of the cracks in the rim which will surely occur. It is highly probable that the cracks in the rim will have big impact on the behaviour of the structure and the big influence on the internal forces in the elements in the structure. This influence of these cracks on the rim is the subject of the further research, as well as finding a suitable computational methodology to include these cracks in a global analysis of the structure.

\section{References}

1. EN 1992-1-1 Design of concrete structures - Part 1-1: General rules and rules for buildings. European Standard (2004)

2. J. Prochazka, Design of concrete structures (Czech concrete society, Prague, 2005)

3. EN 1995-1-1 Design of timber structures - Part 1-1: General-Common rules and rules for buildings (2006)

4. P. Kuklik, Timber structures 10 (Czech Technical University in Prague, Prague, 2002) 